\title{
海藻の揮発成分に関する化学的研究一XII. 海藻揮発成分のミ、ズ筋肉収縮作用についで
}

\author{
片山眥 久

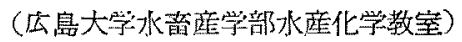 \\ Chemical Studies on Volatile Constituents on Sea-Weeds-XII. \\ Effect on Muscle Contraction of Earthworms \\ Teruhisa Katayama
}

\begin{abstract}
As one of preliminary studies on anthelminthic effect that some seaweeds likely have, an attempt has been made with help of an automatic recorder (Fig. 1) to find which volatile compounds are effective upon muscle contraction of earthworms. Volatile fractions used for the test were obtained from seaweed such as Ulva pertusa K., Enteromorpha sp., Codium, and Sargassum sp.

When the middle segments of a test worm, cut for $2 \mathrm{~cm}$. from the body of about $8 \mathrm{~cm}$. in length, fixed on the hooks of the recorder, were dipped in Ringer solution, the muscle registered normal cycles of contraction (Figs. 1,2). Different oscillations were drawn by the shrinking muscle under the influence of several volatile fractions added at various concentrations to the Ringer fluid (Figs. 3-10). Oi these fractions, carbonyl and terpene, as thin as $0.001 \%$, had strongly contractive effect, while th $\mathrm{m}$ sscle did not seem to react to dimethylsulfide and fatty acids.

The solution of "Machin", a commercial vermicide containing the extract of Digenia simplex, was not so effective as some of the above fractions unless $5 \%$ or more concentrations of the drug was used. Furfurol, found present in carbonyl f raction, made the muscle shrink in its $0.1 \%$ solution.
\end{abstract}

緒言

海藻の揮発成分の蜔虫に対する駆虫作用の予備試験として，さきに系ミ、ズ殺虫刀試験につき報告しだ。 更にミ、ズ筋肉収縮作用につき検討してみた。

ミ、ズ筋肉収縮作用岋 dimethylsulfide 区分, 酸区分, カーボ二ル区分, 脂肪酸及びカーポニル化合物を 除去した中性区分 (テルペン区分)につきキモグラフを用いて測定した結果， dimethylsulfide 区分，酸区 分は何等収綟作用を示さないが，カーボニル区分，テルベン区分は強い収縮作用のあることを知り，カーボ ニル区分とテルペン区分の収縮作用はリングル溶液 $0.001 \%$ に於ても強い収縮作用を示すも市販、クニン錠 は $5 \%$ 溶液に於て初めて収縮作用の起ることを明がした。カーボ二ル区分の $5^{\prime ち}$ furfurol の存在を明加 にしたので)，純 furf urol とつき吟味した結果, 同様収縮作用があること老知つた。從つて海澡の揮発成

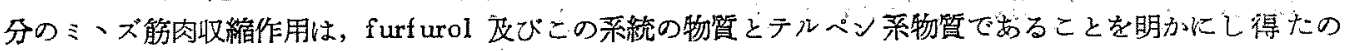
で立に報告する。

\section{実 験之部}

1. 試料 実験に用いた揮発成分はアナナアオサ Uiva pertusa $\mathrm{K}$ ，フォフリ Enteromorpha sp., ミ

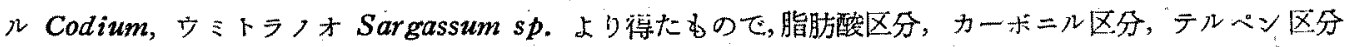
の分劃方法は第 1 報了，第2 報出)に準じた。

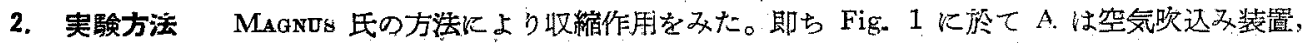

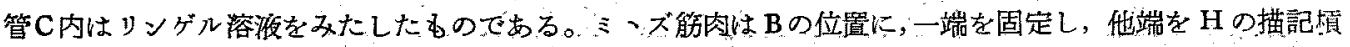

1955 年 11 月 22 日受理

* 本唎究の一部は昭和 26 年 4 月日本水莲学会年会及び昭和 29 年 4 月日本水座学会年会に於て発表した。 
杆にとりつ収縮作用をみた。ミ、ズの大きさは約 $8 \mathrm{~cm}$ のものを用い，頭 部, 尾部各々 $3 \mathrm{~cm}$ 切り取り中央約 $2 \mathrm{~cm}$ を試料として用いた。リンゲル溶 液としては, 1/13M NaCl 100 vol., 1/13 M KCl 1.3 vol., 1/20 M Ca $\mathrm{Cl}_{2} 1.8 \mathrm{vol}$. を混和したもので, この混液に重炭酸ソーダを $0.002 \%$ になる よう添加した。上記の如く切り取つたミ、ズ矣肉は, シャーレ内のリンゲル 溶液に 5 分間入てれ後, C 管内に固定した。

3. 実験結果 ミ、ズ㙝肉の正常運動 ミ、ズ筋肉は Fig. 1 の如く

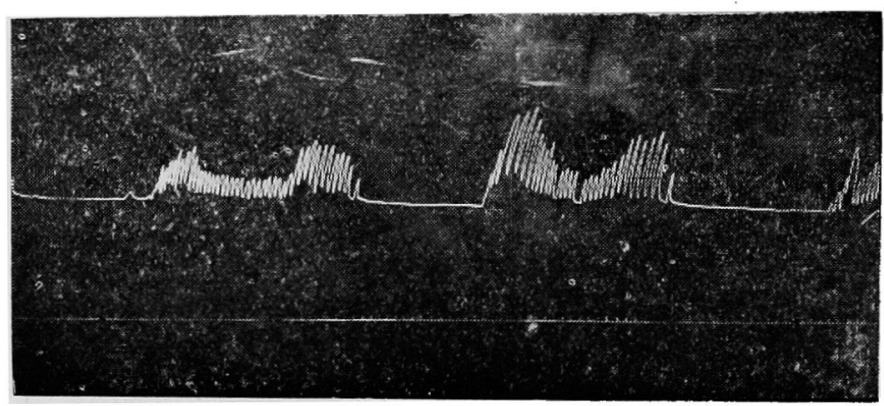

Fig. 2. Trace drawn by contracting muscle in the absence of volatile fractions.

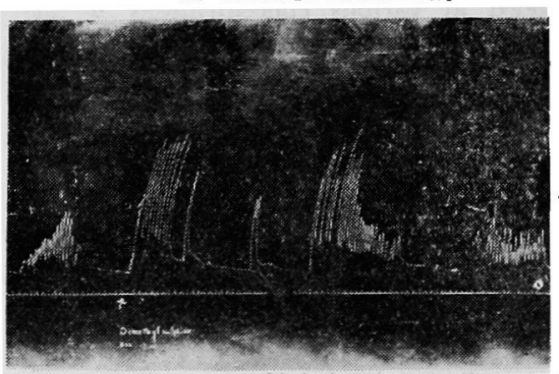

$\leftarrow$ Fig. 3. Trace drawn by contracting muscle due to dimethylulfide. In Figs. 3 through 10 arrow shows the point where a volatile fraction was added.

$\downarrow$ Fig. 4. Trace drawn by contracting muscle due te carbonyl fraction
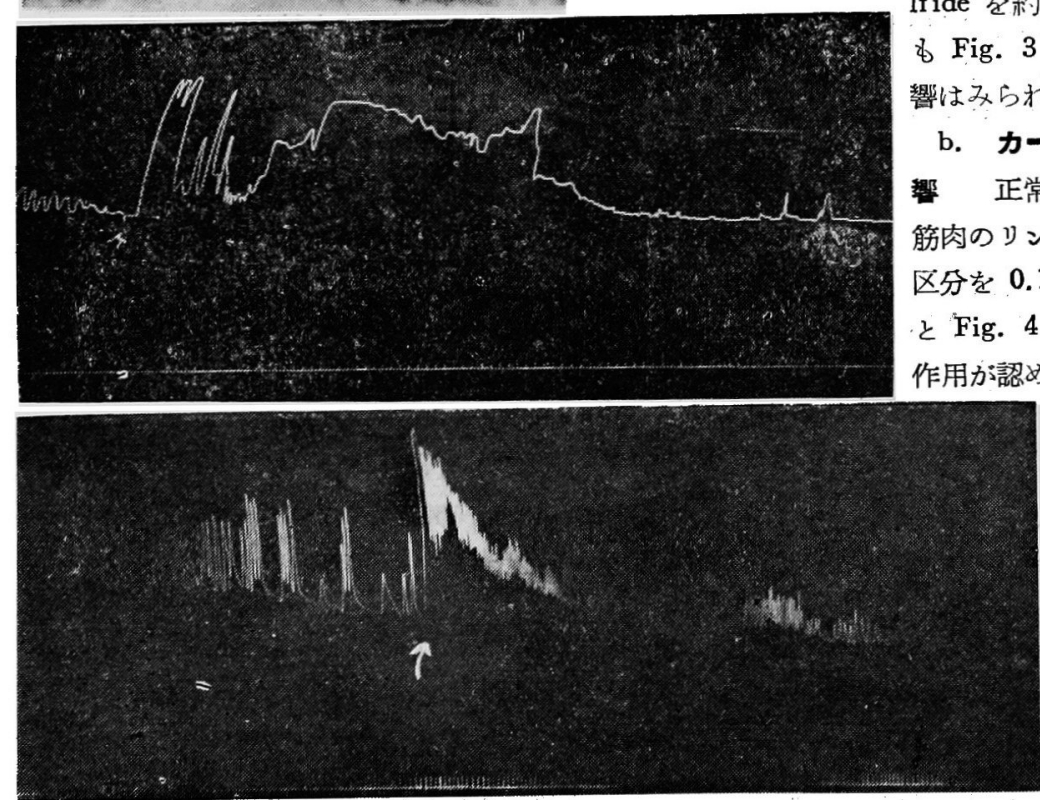

Fig. 5. Trace drawn by contracting muscle due to furfurol fraction.

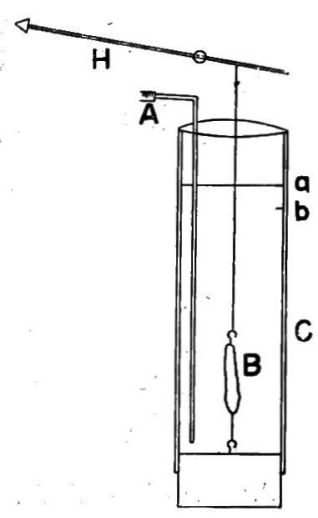

Fig. 1. Device for recording muscle contraction of the test worm.

A : Pipe blowing in air.

B : Segments of the earthworm.

C : Glass tube.

$\mathrm{H}$ : Pen working on lever principle.

固定すると, Fig. 2 のように週 期的な正常の収縮運動を示すので, これを確めて後に検体をリンゲル漼 に添加した。

\section{a. Dimethylsulfide 添加による}

変化上記のような正常運動を行 つているミ、ズ筋肉に dimethylsuIfide を約 $20 \%$ になる も Fig. 3 にみられるように何等影 響はみられなかつた。

b. カーボニル区分添加による影 望正常運動を行つているミ、ズ 筋肉のリンゲル溶液内にカーボニル 区分を $0.1 \%$ になるよに添加する と Fig. 4 に示すよ5に明かに収縮 作用が認められた。

$$
\text { カーホニル区分に }
$$
furfurol の存在を確 認し得たので, furfurol を $0.1 \%$ にな るように添加すると Fig. 5 のよ5に収縮 作用が起つた。

\section{c. 酸区分添加に} よる影整正常運 
1

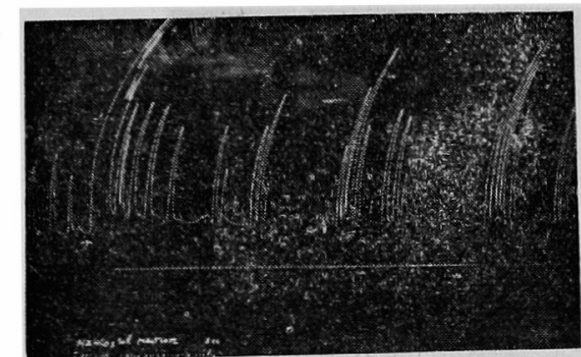

3

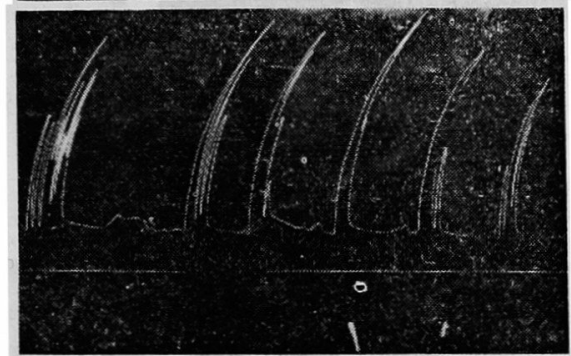

2

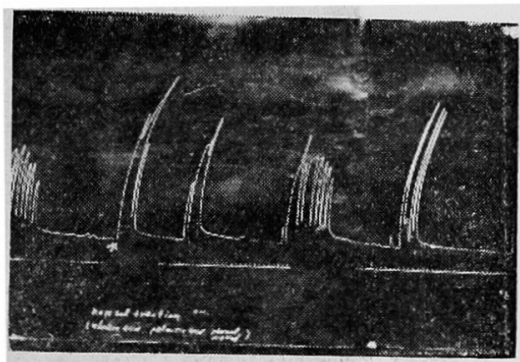

Fig. 6. Trace drawn by contracting muscle due to fatty acid fractions.

1. In the absence of valatile fractions.

2. In the presence of fraction soluble in sodium bicarbonate.

3. In the presence of fraction soluble in potassium hydroxide.

動を行つているミ、ズ筋肉に, 重炭酸ソーダ可溶区, 炭酸ソーダ 可溶区, を $1 \%$ 等变化は認められなかつた。(Fig.6)

d. テルペン区添加による変化 正常運動を行つているミ、ズ筋肉の リンゲル 溶液に中性区分を添加 すると Fig. 7 の上うと収縮作用か認められた。

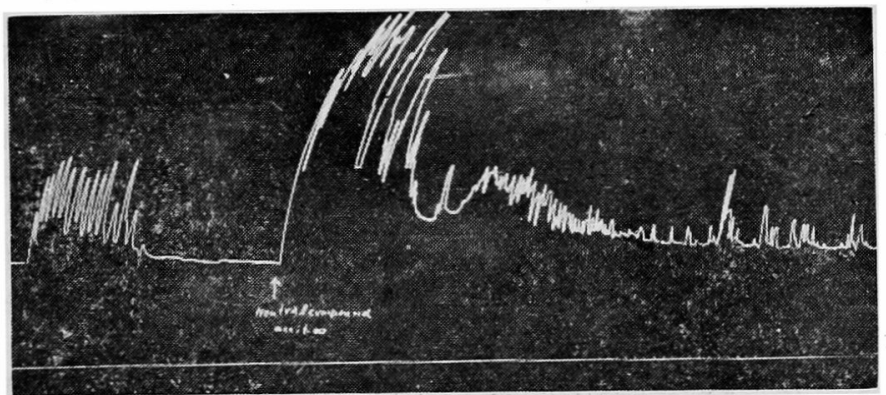

Fig. 7. Trace drawn by contracting muscle due to terpene fraction.

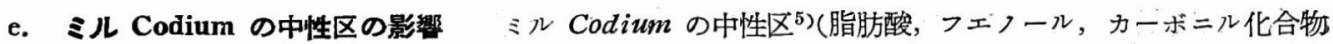
除去）を $0.001 \%$ になるよう添加すると Fig. 8 のようと収縮作用が認められた。

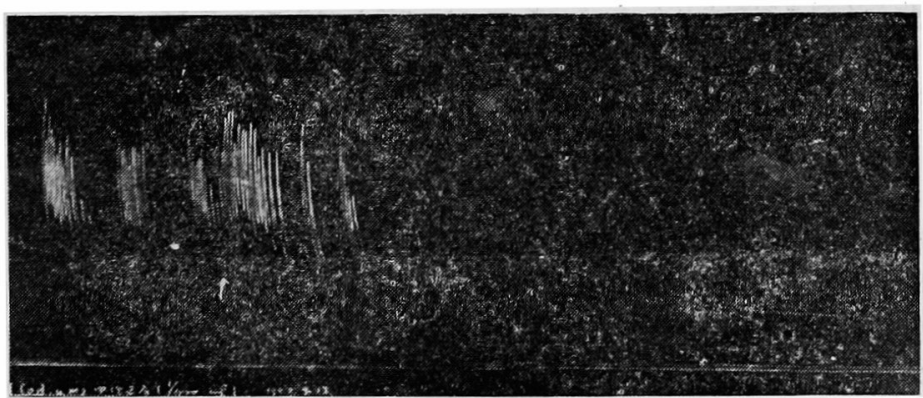

Fig. 8. Trace drawn by contracing muscle due to terpene fraction of Codium.

f. ウミトラノオ Sargassum sp. の中性区の影響 ウミトラノオ Sargassum sp. の中性区分6)を 0.001 \%になるよう添加すると Fig. 9 と示すように収縮作用か認められた。 


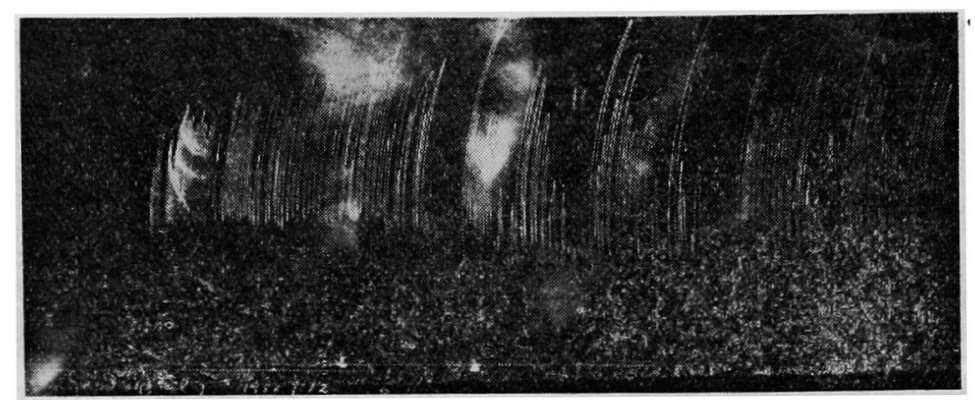

Fig. 9. Trace drawn by contracting muscle due to terpene fraction of Sargassum sp.

g. 市肘マクニン錠の収縮作用 市販マクニン錠（1錠中海人草エキス $0.0075 \mathrm{~g}$ 含有）では $5 \%$ 溶液に なるように加えて初めてミ、ズ能肉収縮作用が認められた。(Fig.10)

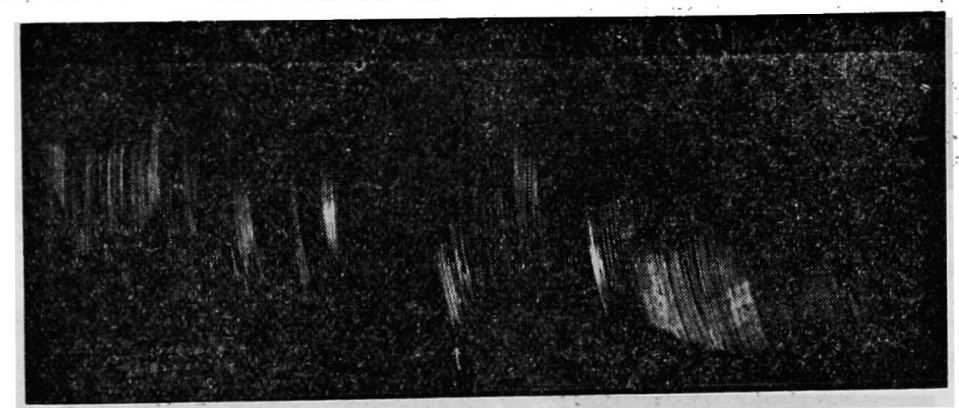

Fig. 10. Trace drawn by contracting muscle due to "Macniñ" solution.

以上のことにより, カーボニル区分のうち furfurol が収縮作用のあることを明かにし，テルペン区分る 強い筋肉の収縮作用のあることを認めた。テルペン系物質についての収縮作用は目下研究続行中である。

\section{1. 総括}

1. 海澡の揮成発分はミ゙スズ筋肉を収縮する作用のあることをキモ゙グラブを用いて明かにした。

2. 海澡の揮発成分の5、ち収縮作用のある区分は, カーボニル区分，テルペン区分であつて dimethylsulfide 区分, 脂肪酸区分以認的られなからた。

3. 中性区分忹 $0.001 \%$ に於ても收縮作用が喼められたが,市販マクニン錠に於ては $5 \%$ 溶液に於て初め て収縮作用がみられた。

4. 中性区分として，ナナアオサ Ulva pertusa，ウミトラノオ Sargassum sp。 ミル Codium 等の揮 発成分より得たものを試料としいられれる同様の結果を得た。

5. カーポニル化合物区に確認された furfurol について検してみると $0.1 \%$ の溶液に於て収縮作用の 起ることを明かにした。

本研究の進展に当り終始御懇切に御指導賜つた九大富山教授, 菒大柴田教授に厚く感謝の意を表する。

\section{文献}

1) 片山輝久: 本誌, 22, 251 (1956).

2) 片山輝久: 本誌, 21, 416 (1955).

3）片山輝久・富山哲夫 : 本誌，17，122 (1952).

4) 片山輝久: 本誌 19, 793 (1953).

5) 片山輝久: 未発表.

6) 片山輝久 : 本誌, 21, 425 (1955). 